\title{
Prototheca cutis sp. nov., a newly discovered pathogen of protothecosis isolated from inflamed human skin
}

Correspondence

Koichi Makimura

makimura@main.teikyo-u.ac.jp
Kazuo Satoh, ${ }^{1,2}$ Kenji Ooe, ${ }^{3}$ Hirotoshi Nagayama ${ }^{3}$ and Koichi Makimura ${ }^{1,4}$

${ }^{1}$ Teikyo University Institute of Medical Mycology, Hachioji, Tokyo, Japan

${ }^{2}$ Japan Health Sciences Foundation, Chuo-ku, Tokyo, Japan

${ }^{3}$ Asahi General Hospital, Asahi, Chiba, Japan

${ }^{4}$ Genome Research Center, Graduate School of Medicine and Faculty of Medicine, Teikyo University, Hachioji, Tokyo, Japan

\begin{abstract}
A strain of a novel pathogenic, achlorophyllic alga belonging to the genus Prototheca was isolated from the inflamed skin of a patient with protothecosis in a Japanese hospital. The pathogen was detected and isolated in biopsy specimens by histopathology and culture-based examination. Analyses of the nuclear 18S rDNA gene and 26S rDNA gene D1/D2 domain sequences and chemotaxonomic studies indicated that this strain represents a novel species with a close phylogenetic relationship to Prototheca wickerhamii and Auxenochlorella protothecoides. This strain grew well at $28-30{ }^{\circ} \mathrm{C}$, showed slow and weak growth at $37{ }^{\circ} \mathrm{C}$, and no growth at $40^{\circ} \mathrm{C}$. This strain grew in vitamin-free medium and assimilated acetate $(\mathrm{pH} 5.1)$, L-arabinose and soluble starch as a carbon source. The taxonomic description of Prototheca cutis sp. nov. is proposed (type strain JCM $15793^{\top}=$ CBS $11262^{\top}=\mathrm{DSM} 22084^{\top}$ ) as a pathogen of dermatitis.
\end{abstract}

Protothecosis is a sporotrichosis-like dermatitis in humans and animals caused by infection with achlorophyllic algae of the genus Prototheca. The genus Prototheca consists of achlorophyllous algae closely related to the green algae of the genus Chlorella (Pore, 1998). Species of the genus Prototheca exist in the environment as ubiquitous detritus inhabitants and contaminants of various substrates. General protothecosis is caused in humans by Prototheca wickerhamii and in domestic animals by Prototheca zopfii. The general symptom is dermatitis or bovine mastitis, and mortal cases are extremely rare. On the other hand, $P$. wickerhamii is a serious pathogen which rarely causes meningitis (Kaminski et al., 1992). Their roles as pathogens of human diseases are largely unknown. However, the incidence of infections caused by unusual organisms is likely to increase with the increasing numbers of immunocompromised individuals throughout the world (LassFlörl \& Mayr, 2007).

In this study, we characterized a pathogenic strain isolated from inflamed skin caused by protothecosis in a patient in a Japanese hospital. Phenotypic, chemotaxonomic, and

The GenBank/EMBL/DDBJ accession number for the $18 \mathrm{~S}$ rDNA gene and $26 \mathrm{~S}$ rDNA gene D1/D2 domain sequences of strain JCM $15793^{\top}$ are $\mathrm{AB} 470468$ and $\mathrm{AB} 470469$, respectively.

Larger versions of Figures 1 and 2, and a phylogenetic tree based on $26 S$ rRNA gene D1/D2 domain sequences are available with the online version of this paper. phylogenetic analyses indicated the strain to be affiliated with the genus Prototheca. The data obtained also suggested that the isolate represents a novel species as a pathogen of dermatitis.

Most of the morphological, biochemical, and physiological characteristics were examined using the methods described by Yarrow (1998). Skin samples obtained by biopsy were subjected to both histopathological and microbiological examinations. For histopathological examination, the sample was digested in diastase and paraffin-embedded pathological specimens were subjected to periodic acidSchiff staining. For microbiological examination, samples were inoculated onto Sabouraud dextrose agar (SDA), and incubated at $35{ }^{\circ} \mathrm{C}$. Assimilation pattern-based identification of the isolate was performed with API 20C AUX V4.0 strips (bioMérieux). Fatty acid methyl esters were determined by TechnoSuruga Laboratory (Shizuoka, Japan). Yeast nitrogen base with amino acids and ammonium sulfate, vitamin free (Y2035; United States Biological), was used as vitamin-free medium.

Genomic DNA from the isolate was extracted and purified according to the protocol recommended for the FTA Classic Card (Whatman). DNA fragments covering the nuclear $18 \mathrm{~S}$ rDNA gene and the 26S rDNA gene D1/D2 domain were amplified by using primers for the $18 \mathrm{~S}$ rDNA gene (SSU-F1 and SSU-R1) and the D1/D2 domain (28SF1 and 635), respectively, as described previously (Sugita 
et al., 2003; White et al., 1990; Xiao et al., 2004). DNA sequencing was performed with an Applied Biosystems model 310 sequencer. A neighbour-joining tree (Saitou \& Nei, 1987) was reconstructed by using MEGA4 (Tamura et al., 2007). Data consistency was tested by bootstrapping the alignments 1000 times with corrections for multiple substitutions.

The patient was a 57-year-old male civil service employee. He does not touch the soil or domestic animals in daily life. The chief condition was a left antebrachial ulcer. He had past histories of diverticulitis (at 35 years), chronic persistent $\mathrm{HCV}$ hepatitis (from 46 years to present), urothelial carcinoma (at 48 years; grade I, treated successfully by endoscopic surgery), diffuse large B-cell malignant lymphoma (at 51 years; achieved complete remission with chemotherapy), and psoriasis vulgaris (at 51-57 years; treated by prednisolone by mouth, $8-15 \mathrm{mg} \mathrm{day}^{-1}$ ). In April 2008, the patient noticed ulcer formation in his forearm without any injury. He visited Asahi General Hospital (Chiba, Japan) in May because the ulcer had not subsided. The affected area showed cellulitis-like dermatitis with ulcer $(70 \times 25 \mathrm{~mm})$. Biopsy was performed under a suspected diagnosis of sporotrichosis (Fig. 1 and Supplementary Fig. S1, available in IJSEM Online). The case was suspected to be protothecosis because a yeast strain was isolated from the biopsy sample and cells typical of the genus Prototheca were observed on histopathological examination (Fig. 2 and Supplementary Fig. S2). Therefore, itraconazole (by mouth, $200 \mathrm{mg}$ day $^{-1}$ ) was prescribed from June. No histopathological characteristics of psoriasis vulgaris were observed. In July, a second biopsy was performed because the dermatitis had improved but rubor and some small abscesses remained. A yeast-like strain was isolated again and cells typical of the genus Prototheca were still observed. Continuous treatment with itraconazole induced remission by October. The yeast-like isolates from May and July were subjected to an assimilation-based identification test by API 20C and both strains were

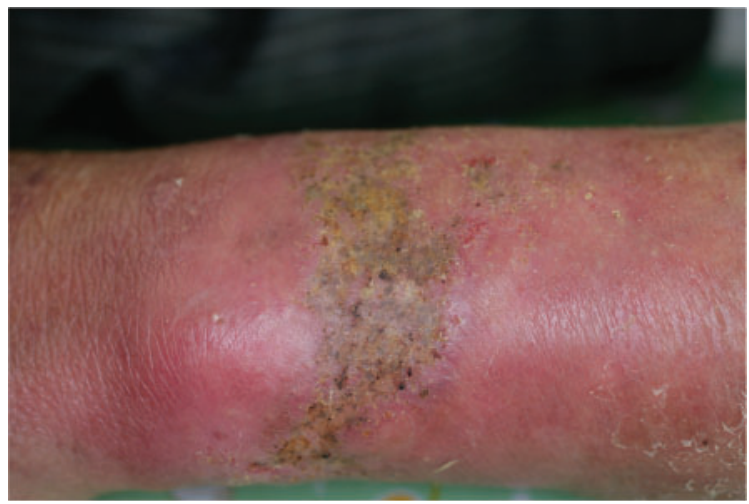

Fig. 1. The symptom that was caused by infection with strain JCM $15793^{\top}$. Cellulitis-like dermatitis with ulcer $(70 \times 25 \mathrm{~mm})$ was observed on the left forearm.

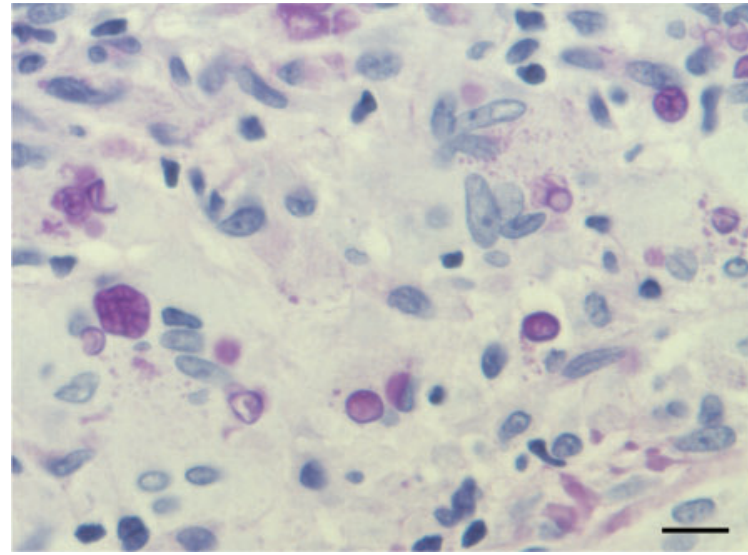

Fig. 2. Histopathological image of biopsy specimen. Bar, $10 \mu \mathrm{m}$.

identified as $P$. wickerhamii with a probability of $99.9 \%$ (API profile: 6240040).

As described in the species description, the main characteristics of strain JCM $15793^{\mathrm{T}}$ (July isolate) did not correspond to those of $P$. wickerhamii but to a novel species. The colonies could grow in the light $(3-30 \mu \mathrm{mol}$ photons $\mathrm{m}^{-2} \mathrm{~s}^{-1}$ ) or dark and were white to ivory with no relation to the light or dark growth conditions. Fig. 3 shows a micrograph of a culture of strain JCM $15793^{\mathrm{T}}$. The strain grew well at $28-30{ }^{\circ} \mathrm{C}$, showed slow and weak growth at $37^{\circ} \mathrm{C}$, and did not grow at $40{ }^{\circ} \mathrm{C}$. Strain JCM $15793^{\mathrm{T}}$ showed slow and weak growth in vitamin-free medium. The percentages of fatty acid methyl esters were as follows: $2.04 \% \mathrm{C}_{14: 0}, 0.51 \% \mathrm{C}_{15: 0}, 0.62 \% \mathrm{C}_{16: 1} \omega 7 c, 19.7 \% \mathrm{C}_{16: 0}$, $0.62 \% \mathrm{C}_{16: 1}, 0.65 \% \mathrm{C}_{17: 1} \omega 8 c, 0.79 \% \mathrm{C}_{17: 0}$, and $4.55 \%$ $\mathrm{C}_{18: 0}$.

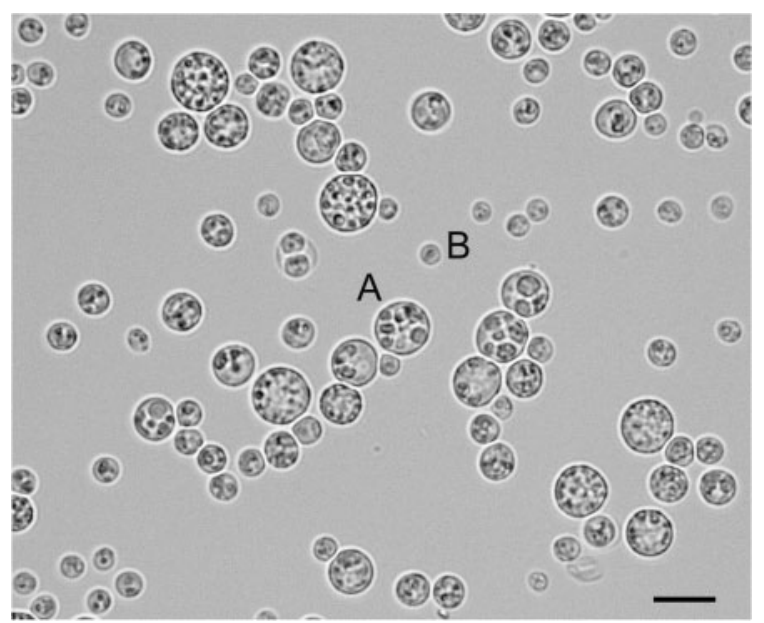

Fig. 3. Culture of strain $\mathrm{JCM} 15793^{\top}$ photographed after an incubation period of 3 days at $30{ }^{\circ} \mathrm{C}$ on Sabouraud dextrose agar plates. A, Sporangia; B, released sporangiospores. Bar, $10 \mu \mathrm{m}$. 
Phylogenetic trees of strain JCM $15793^{\mathrm{T}}$ based on $18 \mathrm{~S}$ rDNA gene and 26S rDNA gene D1/D2 domain sequences are shown in Fig. 4 and Supplementary Fig. S3, respectively. These two neighbour-joining trees suggested that strain JCM $15793^{\mathrm{T}}$ represented a novel species. The $18 \mathrm{~S}$ rDNA gene sequence of JCM $15793^{\mathrm{T}}$ showed 92.2 and $90.5 \%$ similarity to those of $P$. wickerhamii SAG 263-11 and Auxenochlorella protothecoides SAG 211-7 $\mathrm{a}^{\mathrm{T}}$, respectively. The $26 \mathrm{~S}$ rDNA gene D1/D2 region of JCM $15793^{\mathrm{T}}$ showed 86.5 and $82.2 \%$ similarity to those of $P$. wickerhamii SAG263-11 and A. protothecoides SAG 211$7 \mathrm{a}^{\mathrm{T}}$, respectively.

The infection in the present case was an ulcer-forming cellulitis-like dermatitis related to systemic prednisolone or some primary disease. It was not a systemic but superficial infection; however, it should be noted that the novel species could not be distinguished from superficial and systemic infection-causing $P$. wickerhamii by the conventional identification system (Mohabeer et al., 1997).

Strain JCM $15793^{\mathrm{T}}$ clustered with the genus Prototheca, but was different from the recognized species (Fig. 4 \& Supplementary Fig. S3). There have been previous reports of fatty acid methyl ester analysis of the genus Prototheca, but comparison with the present study was not possible due to the different methods used (Roesler et al., 2006; Sud \& Feingold, 1979). However, there are no species closely related to JCM $15793^{\mathrm{T}}$ in The Sherlock Microbial Identification System (MIDI). Since the related species $A$. protothecoides (Fig. 4) has chlorophyll, the cultures become green in the light (Kalina \& Punčochárová, 1987). The culture of JCM $15793^{\mathrm{T}}$ was ivory-white in the light, and therefore did not belong to the genus Auxenochlorella. The typical API profile of $P$. wickerhamii is 6040040. Strain JCM $15793^{\mathrm{T}}$ differed from $P$. wickerhamii in L-arabinose assimilation, but was classified as $P$. wickerhamii showing a non-specific reaction. Furthermore, the results of acetate ( $\mathrm{pH}$ 5.1) and soluble starch assimilation were also different, but API does not support these. Therefore, it was not possible to classify these two species by using the API system. With the exception of Prototheca blaschkeae, members of the genus Prototheca cannot grow in vitaminfree medium and cannot assimilate soluble starch (Pore, 1998). These two characteristics have not been described in P. blaschkeae (Roesler et al., 2006). The recognized species of the genus Prototheca cannot assimilate L-arabinose (Pore, 1998; Roesler et al., 2006). As strain JCM $15793^{\mathrm{T}}$ was different from the recognized species in these characteristics, it was suggested to be a novel species. Strain JCM $15793^{\mathrm{T}}$ was identified as a novel pathogen involved in protothecosis. This strain was not identified with the commercial kit based on carbon assimilation, and was shown to represent a novel species by gene analysis. Therefore, the importance of gene diagnosis will likely increase in the future. Taxonomically, it is desirable that a description of a new species be based on more than one isolate. However, as our novel species grew in vitamin-free medium and assimilated acetate ( $\mathrm{pH}$ 5.1), L-arabinose and soluble starch, this micro-organism appears to be significant as a member of the genus Prototheca. The infection by this isolate was of a cuticle and was not systemic. This is a symptom unlike $P$. wickerhamii. Furthermore, information

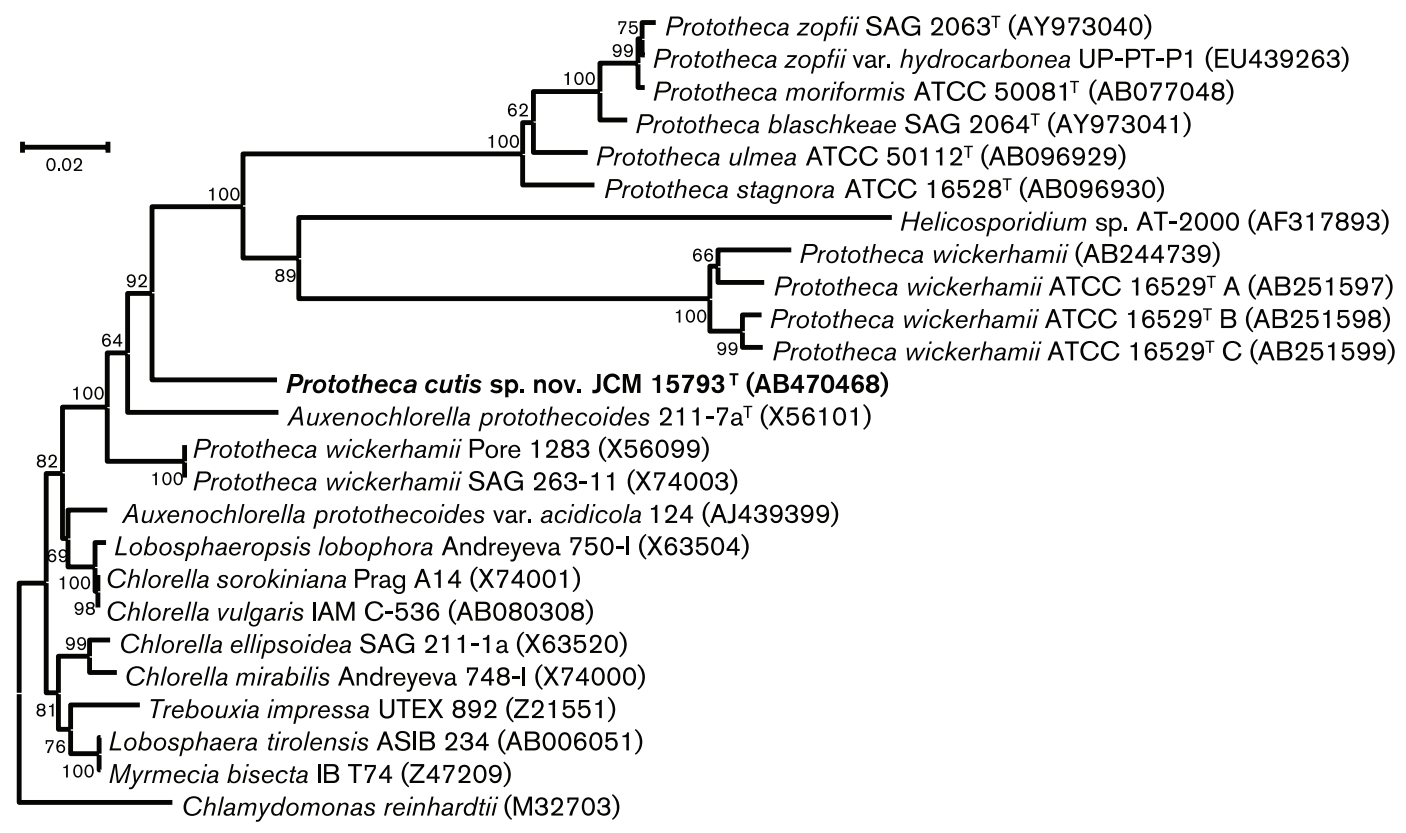

Fig. 4. Phylogenetic tree drawn from neighbour-joining analysis of $18 \mathrm{~S}$ rDNA gene partial sequences, depicting the relationships of strain JCM $15793^{\top}$ with closely related species. Bootstrap percentages over $60 \%$ from 1000 bootstrap replicates are shown. Bar, 0.02 substitutions per nucleotide position. Outgroup: Chlamydomonas reinhardtii (M32703). 
regarding this novel pathogen will help in the treatment of protothecosis. Therefore, we propose a novel species based on this single isolate. In addition, $P$. wickerhamii formed two phylogenetic clusters in this study (Fig. 4 and Supplementary Fig. S3). P. wickerhamii is a historic species that was described 50 years ago and has not yet been subdivided (Pore, 1998; Tubaki \& Soneda, 1959). Therefore, the possibility to re-examine the classification of strains within this species in the future is suggested.

\section{Latin diagnosis of Prototheca cutis Satoh et Makimura sp. nov.}

In liquido YM post dies 3 ad $30{ }^{\circ} \mathrm{C}$, cellulae vegetativae, ovoideae aut globosae, $2.0-8.0 \mu \mathrm{m}$, singulae, binae. Sedimentum formatur. In SDA post dies 3 ad $30{ }^{\circ} \mathrm{C}$, cultura albus ad eboris, glabra, butyracea vel viscida, margine glabra. Assimilat sic: glucosum, D-galactosum, saccharosum (exigue), maltosum (exigue), cellobiosum (exigue), D-trehalosum, lactosum, inulin (exigue), amylum solubile (exigue), Larabinosum, D-glucosaminum (exigue), ethanolum, glycerolum, acidum DL-lacticum, 1-propanolum (exigue), acidum aceticum ( $\mathrm{pH}$ 5.1), fructosum, et mannosum; non respondent, L-sorbosum, melibiosum, D-raffinosum, D-melezitosum, D-xylosum, D-arabinosum, ribosum, L-rhamnosum, $N$ acetyl-D-glucosaminum, methanolum, erythritolum, ribitolum, galactitolum, D-mannitolum, D-glucitolum, methyl $\alpha$ D-glucosidium, salicinum, acidum gluconicum, acidum succinicum, inositolum, hexadecanum, nec 2-ketogluconatum. Ammonium sulfatum et cadaverinum (exigue), assimilantur at non natrium nitrosum, kalium nitricum, ethylaminum, nec L-lysinum. Arginine non assimilantur. Ad crescentiam vitaminum non necessarium est (exigue). Augmentum in $28{ }^{\circ} \mathrm{C}-30{ }^{\circ} \mathrm{C}$, crescit in $37{ }^{\circ} \mathrm{C}$, non crescit in $40{ }^{\circ} \mathrm{C}$. Typus stirps JCM $15793^{\mathrm{T}}$ ex auris proluvier homine, Japonia, isolata est. In collectionibus culturarum quas Japan Collection of Micro-organisms, Wako, Saitama, sustentant, no. JCM $15793^{\mathrm{T}}$, Centraalbureau voor Schimmelcultures, Delphi Batavorum, sustentant, no. CBS $11262^{\mathrm{T}}$, et Deutsche Sammlung von Mikroorganismen und Zellkulturen, Braunschweig, Germany, sustentant, no. DSM $22084^{\mathrm{T}}$ deposita est.

\section{Description of Prototheca cutis Satoh \& Makimura sp. nov.}

Prototheca cutis (cu'tis. L. gen. f. n. cutis of the skin, isolated from the skin of a human patient).

After 3 days in YM broth at $30{ }^{\circ} \mathrm{C}$, cells are ovoid to globose, 2.0-8.0 $\mu \mathrm{m}$, and single. Sediment is formed. After 3 days on Sabouraud dextrose agar at $30{ }^{\circ} \mathrm{C}$, the streak culture is butyrous to viscous, white to ivory, smooth and glistening with an entire margin. The following carbon compounds are assimilated: glucose, D-galactose, sucrose (weak), maltose (weak), D-cellobiose (weak), D-trehalose, lactose (weak), inulin (weak), soluble starch, L-arabinose, D-glucosamine (weak), ethanol, glycerol, DL-lactate, 1propanol (weak), acetate ( $\mathrm{pH} 5.1)$, fructose and mannose.
The following are not assimilated: L-sorbose, melibiose, Draffinose, D-melezitose, D-xylose, D-arabinose, ribose, Lrhamnose, $N$-acetyl-D-glucosamine, methanol, erythritol, ribitol, galactitol, D-mannitol, sorbitol, $\alpha$-methyl-D-glucoside, salicin, D-gluconate, succinate, citrate, inositol, hexadecane and 2-keto-D-gluconate. Ammonium sulfate and cadaverine (weak) are utilized as sole sources of nitrogen; sodium nitrite, potassium nitrate, ethylamine and L-lysine are not utilized. Arginine is not utilized. Growth in vitamin-free medium is positive, slow and weak. Optimum growth temperature is $28-30{ }^{\circ} \mathrm{C}$; growth is positive at $37{ }^{\circ} \mathrm{C}$, negative at $40{ }^{\circ} \mathrm{C}$.

The type strain, JCM $15793^{\mathrm{T}}$, was isolated from inflamed skin of a male patient at Asahi General Hospital (Chiba, Japan). This strain has been deposited in the Japan Collection of Micro-organisms, Wako, Saitama, as JCM $15793^{\mathrm{T}}$, the Yeast Division of the Centraalbureau voor Schimmelcultures, Delft, the Netherlands, as CBS $11262^{\mathrm{T}}$, and the Deutsche Sammlung von Mikroorganismen und Zellkulturen, Braunschweig, Germany, as DSM $22084^{\mathrm{T}}$.

\section{Acknowledgements}

This study was supported in part by Health Science Research Grants for Research on Emerging and Re-emerging Infectious Diseases from the Ministry of Health, Labor, and Welfare of Japan (K. M.).

\section{References}

Kalina, T. \& Punčochářová, M. (1987). Taxonomy of the subfamily Scotiellocystoideae Fott 1976 (Chlorellaceae, Chlorophyceae). Arch Hydrobiol 73, 473-521.

Kaminski, Z. C., Kapila, R., Sharer, L. R., Kloser, P. \& Kaufman, L. (1992). Meningitis due to Prototheca wickerhamii in a patient with AIDS. Clin Infect Dis 15, 704-706.

Lass-Flörl, C. \& Mayr, A. (2007). Human protothecosis. Clin Microbiol Rev 20, 230-242.

Mohabeer, A. J., Kaplan, P. J., Southern, P. M., Jr \& Gander, R. M. (1997). Algaemia due to Prototheca wickerhamii in a patient with myasthenia gravis. J Clin Microbiol 35, 3305-3307.

Pore, R. S. (1998). Prototheca Krüger. In The Yeasts, a Taxonomic Study, 4th edn, pp. 883-887. Edited by C. P. Kurtzman \& J. W. Fell. Amsterdam: Elsevier.

Roesler, U., Möller, A., Hensel, A., Baumann, D. \& Truyen, U. (2006). Diversity within the current algal species Prototheca zopfii: a proposal for two Prototheca zopfii genotypes and description of a novel species, Prototheca blaschkeae sp. nov. Int J Syst Evol Microbiol 56, 14191425.

Saitou, N. \& Nei, M. (1987). The neighbor-joining method: a new method for reconstructing phylogenetic trees. Mol Biol Evol 4, 406425.

Sud, I. J. \& Feingold, D. S. (1979). Lipid composition and sensitivity of Prototheca wickerhamii to membrane-active antimicrobial agents. Antimicrob Agents Chemother 16, 486-490.

Sugita, C., Makimura, K., Murai, Y., Yamaguchi, H. \& Nagai, N. (2003). A case of pulmonary aspergilloma molecular biological identification and typing of the isolates from antemortem sputa and autopsy fungus ball. Mycoses 46, 149-152. 
Tamura, K., Dudley, J., Nei, M. \& Kumar, S. (2007). MEGA4: molecular evolutionary genetics analysis (MEGA) software version 4.0. Mol Biol Evol 24, 1596-1599.

Tubaki, K. \& Soneda, M. (1959). Cultural and taxonomic studies on Prototheca. Nagaoa (Mycol J Nagao Inst Tokyo) 6, 25-34.

White, T. J., Bruns, T., Lee, S. \& Taylor, J. (1990). Amplification and direct sequencing of fungal ribosomal RNA genes for phylogenetics. In PCR Protocols: a Guide to Methods and Applications, pp. 315-322.
Edited by M. A. Innis, D. H. Gelfand, J. J. Sninsky \& T. J. White. New York: Academic Press.

Xiao, L., Fayer, R., Ryan, U. \& Upton, S. J. (2004). Cryptosporidium taxonomy: recent advances and implications for public health. Clin Microbiol Rev 17, 72-97.

Yarrow, D. (1998). Methods for the isolation, maintenance and identification of yeasts. In The Yeasts, a Taxonomic Study, 4th edn, pp. 77-100. Edited by C. P. Kurtzman \& J. W. Fell. Amsterdam: Elsevier. 